\title{
Geography and Traditional Therapies Utilization: A Convergence of Health Behaviors in Rural and Urban Settings?
}

\section{Padmore Adusei Amoah and Razak Mohammed Gyasi}

Department of Sociology and Social Policy, Faculty of Social Sciences, Lingnan University, Hong Kong SAR

*Corresponding author: Razak Mohammed Gyasi, PhD Student Lingnan University, Department of Sociology and Social Policy, Faculty of Social Sciences, Lingnan University, No. 8 Castle Peak Road, New Territories, Tuen Mun, Hong Kong SAR, Tel: 8525133 9954; E-mail: razak.mgyasi@gmail.com

Rec date: December 12, 2015 Acc date: December 22, 2015 Pub date: December 28, 2015

Copyright: @ 2015 Amoah PA, et al. This is an open-access article distributed under the terms of the Creative Commons Attribution License, which permits unrestricted use, distribution, and reproduction in any medium, provided the original author and source are credited.

\section{Commentary}

Interest in traditional medicine utilization is burgeoning in Ghana and worldwide. Whereas one in seven people in Ghana utilize one sort of traditional medicine or another over the past decades, Complementary and Alternative Medicine (CAM) has become widely used in Asia and advanced environments or elsewhere. The 2007 National Health Interview Survey by the National Centre for Complementary and Alternative Medicine (NCCAM) and the National Centre for Health Statistics for example show, that approximately $38 \%$ of adults in the United States were using some forms of CAM, and accordingly, total expenditure for CAM therapies was estimated at $\$ 34$ billion in 2007 [1]. Estimates in 2010 show that over 244 medicinal plant products, representing 186-209 species and 951 tons of crude herbal medicine are available at Ghana's herbal markets with a total value of more than US\$ 7.8 million [2,3].

So intense in this interest, the relationship between location and traditional medicine use have enjoyed a considerable debate in the policy making and implementation grounds and academic literature arena for well over many decades. The current erudition suggests a mixed pattern of traditional medicine use, taking location and geographical perspectives into consideration. Previous studies, particularly in the economically developed communities have highlighted spatial disparities in the traditional medical services use [4-8]. Despite this overly supported assertion, other studies in the far south report otherwise.

The original empirical paper entitled, "Does spatial location matter? Traditional therapy utilisation among the general population in a Ghanaian rural and urban setting" by Razak Mohammed Gyasi et al. [9] which appears in Volume 23, issue 2 of the Complementary Therapies in Medicine is one of the contemporary research outputs that supports the argument of the latter. The paper espoused a retrospective cross-sectional and place-based research technique involving a representative sample of 324 of rural-urban character with diverse socio-economic and cultural spectra. The study is well written and makes some very important observations. These findings are unique and present an opportunity to re-evaluate the discourse on rural-urban disparities in health behaviours and medical services choices.

It is thought-provoking and theoretically grounded to report that knowledge on traditional medicine, various modalities of traditional medicine and the sources of traditional medicine vary significantly among the general adult population between geographically delimited rural and urban areas. Given differences in baseline characteristics of individuals on the one hand, and the diverse political, socio-cultural, ethnic and environmental orientations across space as well as the various levels of social network types and cohesion on the other hand, one would expect specific variances in the form of traditional medical modalities accessed, information sources and sources of traditional medicine between rural-urban spectrum.

Of a greater interest is the fact that the study reports no significant variance in traditional health services use despite a relatively marginal difference between rural and urban settings. This finding appears unusual considering the pool of research discoveries in this field, globally. However, the finding is not very much astonishing in the African perspective where cultural beliefs and social networks, to a larger degree influence health behaviours of culturally and ethnicspecific groups. Most people in the Ghanaian rural and urban communities are highly linked-up with their cultural and traditional values which entrenches traditional medical system. In addition, the traditional medicine consumption is a central share of the traditional system and therefore permeates personal and socioeconomic attributes of the people.

The finding is an indication of the changing rural characteristics and the rising socioeconomic similarities between rural and urban areas. According to contemporary surveys, traditional medicine use is tacit beyond the baseline sociodemographic traits-income, education, gender, residence-of people [10]. The falling values and utilities and the perceived general dissatisfaction associated with the western biomedical treatments tend to heighten the interest in use of traditional medicine across rural-urban landscape. These mechanisms may well elucidate the universality and widespread use of traditional therapies. The use of traditional medicine is subject to its potency, health-illness perception and the disease etiology, rather than where one lives [11-13]. It is on this note that Gyasi et al. [12] opined that:

"Traditional medicine is characterised by a holistic approach to the spirit-mind-body concept of health, embracing people, living and inanimate objects in an inseparable whole from which all beings derive their living and healing forces. Traditional medicine practice involves a multifaceted combination of activities, order of knowledge, beliefs and customs to generate the desired effects for the diagnosis, prevention or elimination of imbalances in physical, psychological and social wellbeing".

Again, the effect of migration and urbanisation may be reckoned. There is the tendency that rural-urban migrants settle in urban communities with their old ways of treating their afflictions. The formation of new acquaintances in urban localities by newly migrated rural dwellers transmits knowledge and popularity of traditional medicine within their new circles. Personal health philosophies of people in both rural and urban prefectures invariably have a big role to play in the decision to access and use of traditional medical modalities.

We must not lose sight from the fact that the proliferation of mass media outlets including frequency modulation channels, television and 
especially information centres-quasi radios commonly in rural communities-have also expanded the choices of both rural and urban dwellers with regard to health services. Aside from availability of ingredients for traditional medicine in urban areas, traditional medicine has now been modernised and/or formalised into the conventional health system $[14,15]$. This has raised trust in traditional medical practices and may significantly explain the convergence of traditional medicine use and perhaps the general health behaviours between rural and urban dwellers. Taking these into consideration, it is no coincidence that this important study by Gyasi and colleagues [9] highlight on these crucial issues.

It must be recapitulated that spatial dimensions in traditional medical therapies use are receding due to the convergence of health behaviours in rural and urban settings. Given these findings regarding the widespread and still, growing rate of use of traditional medical services, it is important to critically reassess the planning standards for health services in Ghana. A rapid improvement and modernisation of traditional medicine through registration and training of practitioners, clinical examination of herbal drugs and monitoring of dispensing and administration of the therapies are critical. For, these are the antecedents for integrative medicine and intercultural health care in Ghana. Traditional medical therapies of all forms should not be consigned to the peripheries of the western health policy. We again argue that the national health insurance package introduced to provide affordable health care, especially for the indigent and the ultra-poor and/or vulnerable population sector be extended to cover the diagnosis, medical treatment and medication expenditure of traditional health care in Ghana.

\section{References}

1. National center for complementary and alternative medicine (2013) Statistics on complementary and alternative medicine national health interview survey.

2. Andel TV, Myren B, van Onselen S (2012) Ghana's herbal market. Journal of Ethnopharmacology 140: 368-378.

3. Wodah D, Asase A (2012) Ethnopharmacological use of plants by Sisala traditional healers in northwest Ghana. Pharmaceutical Biology 50(7): 807-815

4. Adams J, Sibbritt D, Broom A, Loxton D, Pirotta M, et al. (2011) A comparison of complementary and alternative medicine users and use across geographical areas: A national survey of 1,427 women. BMC Complementary and Alternative Medicine 11: 85.

5. Jirojwong S, MacLennan R (2012) Management of episodes of incapacity by families in rural and remote Queensland. Aust J RuralHealth 10: 249-55.

6. Shreffler-Grant J, Hill W, Weinert C, Nichols E, Ide B (2007) Complementary therapy and older rural women: who uses it and who does not? Nurs Res 56: 28-33.

7. Adrews GJ, Adams J, Segrott J (2010) Complementary and alternative medicine (CAM): production, consumption, research; In: Brown $T$, McLafferty S, Moon G, editors. A companion to health and medical geography. Oxford: Wiley Blackwell: 587-603.

8. Adams J, Sibbritt D, Lui CW (2011) The urban-rural divide in complementary and alternative medicine use: a longitudinal study of 10,638 women. BMC Complement Altern Med 11: 2. doi: 10.1186/1472-6882-11

9. Gyasi RM, Asante F, Segbefia AY, Kabila A, Mensah CM, et al. (2015) Does spatial location matter? Traditional therapy utilisation among the general population in a Ghanaian rural and urban setting. Complementary Therapies in Medicine 23(2): 439-450.

10. Gyasi RM, Asante F, Abass K, Yeboah JY, Adu-Gyamfi S, et al. (in press) Beyond demographics: A qualitative study of health beliefs and motivation for complementary and alternative medicine use in ruralurban context, Ghana, J of Comm Health.

11. Sato A (2012) Do Inequalities in Health Care Utilization in Developing Countries Change When We Take into Account Traditional Medicines? World Development 40(11), 2275-2289.

12. Gyasi RM, Siaw LP, Mensah CM (2015) Prevalence and patterns of traditional medical therapies utilisation in Kumasi Metropolis and Sekyere South District, Ghana. J Ethnopharmacol 161: 138-46.

13. Gyasi RM, Mensah CM, Siaw LP (2015) Predictors of traditionalmedicines utilisation in the Ghanaian health care practice:interrogating the Ashanti Region. J Community Health 40: 314-25,

14. Essegbey GO, Awuni S, Essegbey IT, Akuffobea M, Micah B (2014) Country study on innovation, intellectual property and the informal economy: Traditional herbal medicine in Ghana. World Intellectual Property Organisation (Vol. Committee on Development and Intellectual Property (CDIP), Thirteenth Session). Geneva: World Intellectual Property Organisation (WIPO).

15. Gyasi RM (2015) Relationship between health insurance status and the pattern of traditional medicine utilisation in Ghana. Evidence-Based Complementary and Alternative Medicine, Vol. 2015, ID 717926 